\title{
Association of socioeconomic status with inflammatory markers: A two cohort comparison
}

\author{
Sílvia Fraga a,*, Pedro Marques-Vidal ${ }^{\mathrm{b}}$, Peter Vollenweider ${ }^{\mathrm{c}}$, Gérard Waeber ${ }^{\mathrm{c}}$, Idris Guessous ${ }^{\mathrm{b}, \mathrm{d}, \mathrm{e}}$, \\ Fred Paccaud ${ }^{\text {b }}$, Henrique Barros ${ }^{\text {a }}$, Silvia Stringhini ${ }^{\text {b }}$ \\ a EPIUnit-Institute of Public Health - University of Porto, Porto, Portugal \\ b Institute of Social and Preventive Medicine, Lausanne University Hospital, Lausanne, Switzerland \\ c Department of Medicine, Internal Medicine, CHUV and Faculty of Biology and Medicine, Lausanne, Switzerland \\ d Unit of Population Epidemiology, Geneva University Hospital, Geneva, Switzerland \\ e Department of Epidemiology, Rollins School of Public Health, Emory University, Atlanta, USA
}

\section{A R T I C L E I N F O}

Available online 5 December 2014

Keywords:

Socioeconomic status

Inflammation

Switzerland

Portugal

\section{A B S T R A C T}

Objective. To assess the association between socioeconomic status (SES) and inflammatory markers using two different European population samples.

Methods. We used data from the CoLaus ( $N=6412$, Lausanne, Switzerland) and EPIPorto ( $N=1205$, Porto, Portugal) studies. Education and occupational position were used as indicators of socioeconomic status (SES). High-sensitivity C-reactive protein (hs-CRP) was available for both cohorts. Interleukin-6 (IL-6) and tumour necrosis factor- $\alpha$ (TNF- $\alpha$ ) were available in CoLaus; leukocyte count and fibrinogen in EPIPorto.

Results. We showed that low SES was significantly associated with high inflammation in both studies. We also showed that behavioural factors contributed the most to SES differences in inflammation. In both studies the larger difference between the lowest and the highest SES was observed for hs-CRP. In the Swiss sample, a linear association between education and hs-CRP persisted after adjustment for all mediating factors and confounders considered ( $\mathrm{p}$ for linear trend $<0.001$ ).

Conclusion. Large social differences exist in inflammatory activity, in part independently from demographic and behavioural factors, chronic conditions and medication use. SES differences in inflammation are also similar in countries with different underlying socioeconomic conditions.

(C) 2014 Elsevier Inc. All rights reserved.

\section{Introduction}

Inflammation is a biological response of the immune system that is recognized as an important mechanism in the pathogenesis of atherosclerosis (Fahdi et al., 2003), as a risk factor for cardiovascular disease (Pearson et al., 2003; Willerson and Ridker, 2004), diabetes mellitus (Duncan et al., 2003; Pradhan et al., 2001), and cancer (Allin and Nordestgaard, 2011), and is also associated with increased mortality (Harris et al., 1999; Reuben et al., 2002). There is evidence to suggest that people exposed to social adversity have higher inflammatory status (Alley et al., 2006; Deverts et al., 2012; Jousilahti et al., 2003; Koster et al., 2006), i.e., high levels of C-reactive protein, serum amyloid A, fibrinogen, leukocyte count and cytokines. The impact of the social environment on inflammatory status can be explained by several processes. First, exposure to an adverse work environment elicits

\footnotetext{
* Corresponding author at: Rua das Taipas 135, 4050-600 Porto, Portugal. Fax: + 351 222061820.

E-mail address: silfraga@med.up.pt (S. Fraga).
}

sustained stress reactions which impact inflammation; these exposures are likely to be experienced more frequently by socioeconomically disadvantaged groups (Siegrist and Marmot, 2004). Second, because of their increased vulnerability, individuals of lower socioeconomic status (SES) present a higher susceptibility to infections (Cohen, 1999; Cohen et al., 2004) and higher risk for chronic diseases (Galobardes et al., 2006b; Kaplan and Keil, 1993; Lawlor et al., 2003; Stringhini et al., 2012b). Although inflammation can be either a cause or a consequence of chronic diseases, in this study we consider chronic diseases as potential confounders of the SES-inflammation association. Finally, unhealthy behaviours such as smoking, heavy drinking, physical inactivity and BMI $\geq 30 \mathrm{~kg} / \mathrm{m}^{2}$ might also account for the link between low SES and higher inflammatory status, as they are related to higher levels of inflammatory markers (Colbert et al., 2004; Frohlich et al., 2003; Imhof et al., 2001) and are also more common among people with a low SES (Alley et al., 2006; Koster et al., 2006; Stringhini et al., 2012a).

It is well established that low SES is related to higher levels of inflammation (Adler et al., 1993; Alley et al., 2006; Deverts et al., 2012; Hemingway et al., 2003; Koster et al., 2006; Stringhini et al., 2013). 
However, multicounty comparison is limited by the variety of SES indicators examined and the lack of harmonisation across studies. The study of this relationship in different settings can contribute to the understanding of the extent to which the environment in which people live influences the social patterning of inflammation. Thus, the present study aims to assess the association between SES and inflammatory markers using data from two population-based European cohorts with comparable design with regard to assessment of SES, health behaviours, chronic conditions and inflammatory markers: the CoLaus study (Lausanne, Switzerland, Central Europe) and the EPIPorto study (Porto, Portugal, South-western Europe). Given the large socioeconomic differences between Portugal and Switzerland, we hypothesize that the influence of SES on inflammation would be different in the two countries.

\section{Participants and methods}

Two European cohort studies provided data for our analyses: the CoLaus study (Lausanne, Switzerland) and the EPIPorto study (Porto, Portugal).

\section{The CoLaus study}

The CoLaus study was initiated in 2003 and recruited 6738 participants aged between 35 and 75 years in the city of Lausanne. More details on the CoLaus can be found elsewhere (Firmann et al., 2008; Marques-Vidal et al., 2011; Stringhini et al., 2012a). For the present analysis, we included data from the CoLaus wave 1 (2003-2006). From the initial 6738 CoLaus participants, exclusions were made because of missing information on education $(\mathrm{N}=18)$ or because hsCRP values were higher than $10 \mathrm{mg} / \mathrm{L}(\mathrm{N}=313)$. Hence, 6412 CoLaus participants ( 3351 women) were included in the present analysis. No significant differences were found between included and excluded participants for sociodemographic indicators and health behaviours. Analysis on occupational position was further restricted to 4586 participants (1099 women), as information on occupational position was only available for those participants who were currently working. Excluded participants (i.e., non-working participants) were older $($ mean $=61(S D=10.4)$ vs. mean $=49(S D=8.8)$, $\mathrm{p}<0.001)$ and they were more likely to be women $(\mathrm{OR}=2.23$; $95 \% \mathrm{CI}: 1.99,2.50)$, low educated (OR $=2.18 ; 95 \% \mathrm{CI}: 1.94,2.44)$, and obese $(\mathrm{OR}=1.66 ; 95 \% \mathrm{CI}: 1.46,1.89)$ and less likely to be smokers $(\mathrm{OR}=0.69 ; 95 \% \mathrm{CI}: 0.60,0.78)$.

\section{The EPIPorto study}

The EPIPorto study was initiated in 1999 and recruited 2485 adult dwellers aged 18 years or more in the city of Porto. More details about the recruitment can be found elsewhere (Pereira et al., 2012; Santos and Barros, 2003). For the present analysis we included data from the EPIPorto wave 2 (2005-2008). Among the 1682 participants who participated in the EPIPorto wave 2 (68\% of the baseline sample), 477 were not included in the present analysis ( 325 because they were $<35$ or $>75$ years and thus not comparable with the CoLaus age range; 154 with hs-CRP levels $>10 \mathrm{mg} / \mathrm{L}$ and 77 with leukocytes $\left.>11 \times 10^{9} / \mathrm{L}\right)$. In the final analysis 1205 ( 772 women) participants were thus included. As in the CoLaus study, analysis on occupational position was further restricted to 1099 participants (677 women). No significant differences were found between included and excluded participants for sociodemographic indicators and health behaviours.

\section{Data collection}

In both studies, data were collected by trained interviewers through structured questionnaires and venous samples were drawn after an overnight fast.

\section{Socioeconomic status}

Two commonly used indicators of SES were used: education and occupational position. In both studies, educational level was assessed as the highest qualification achieved and categorized as "high" (tertiary education), "medium" (upper secondary education) and "low" (lower secondary education or lower) (UNESCO, 2011). Participants' occupational position was categorized as "high" (professional and managerial occupations), "medium" (non-manual and manual skilled occupations) and "low" (semi-skilled and unskilled occupations) (Galobardes et al., 2006a).

\section{Inflammatory markers}

In the CoLaus study, high-sensitivity C-reactive protein (hs-CRP, $\mathrm{mg} / \mathrm{L}$ ) was assessed by immunoassay and latex HS (IMMULITE 1000-High, Diagnostic Products Corporation, Los Angeles, CA, USA). Interleukin-6 (IL-6) and tumour necrosis factor- $\alpha$ (TNF- $\alpha$ ) levels were measured using a multiplexed particle-based flow cytometric cytokine assay (Vignali, 2000).

Milliplex kits were purchased from Millipore (Zug, Switzerland). The procedures closely followed the manufacturer's instructions. The analysis was conducted using a conventional flow cytometer (FC500 MPL, Beckman Coulter, Nyon, Switzerland). Values lower than the detection limit $(0.2 \mathrm{pg} / \mathrm{mL})$ were assigned a value equal to half the detection limit (Hornung and Reed, 1990). This was done for 360 (8.4\%) and 35 (0.8\%) participants for IL-6 and TNF- $\alpha$, respectively.

In the EPIPorto study, hs-CRP was assessed through particleenhanced immunonephelometry using a Behring auto-analyser, Nephelometer II, BN II (Dade Behring Marburg GMBH, Germany). Total blood leukocyte count was used as $\left(\times 10^{9} / \mathrm{L}\right)$. Fibrinogen was assessed through coagulometry.

Participants with hs-CRP levels higher than $10 \mathrm{mg} / \mathrm{L}$ in both studies and leukocytes $>11 \times 10^{9} / \mathrm{L}$ in EPIPorto were excluded from the analysis since these values were likely to represent an acute condition, and we intended to focus on chronic inflammation.

\section{Health behaviours}

Current smoking was assessed using a questionnaire on current smoking status and was classified as yes/no. Former smokers were included in the non-smoker category. Alcohol consumption was self-reported and classified according to weekly consumption as abstainers ( 0 unit/week), moderate drinkers (1-21 units/week for men and 1-14 units/week for women) or heavy drinkers $(\geq 21 / \geq 14$ units/week for men/women). Participants were classified as physically active if they reported participating in a physical activity of more than 20 min once a week or more, and as physically inactive otherwise. Body weight and height were measured with participants standing without shoes in light indoor clothing. Body mass index (BMI) was calculated as weight $(\mathrm{kg}$ ) divided by height squared $\left(\mathrm{m}^{2}\right)$ (World Health Organization, 2007). The standard deviation scores of BMI (BMI z-score) were also used in the present analysis.

\section{Chronic conditions and medication use}

Participants were asked about the presence of respiratory diseases, cancer, heart disease, diabetes, hypertension, inflammation-related conditions and depression. In both cohorts, current medication use was recorded and coded according to the Anatomic Therapeutic Chemical (ATC) classification system. For the present analysis, we considered only the regular use of anti-inflammatory products, non-steroids (MO1A) and corticosteroids for systemic use (H02). 


\section{Demographics}

Demographics included gender, age and cohabitation. Living in couple was defined based on marital status (married/living common law vs. single or divorced or widow).

\section{Ethics statement}

The CoLaus study was approved by the Institutional Ethics Committee of the University of Lausanne (Switzerland) and the EPIPorto study was approved by the Ethics Committee of Porto Medical School Hospital São João (Portugal). In both studies, written informed consent was obtained from all participants.

\section{Statistical analysis}

All analyses were performed using the statistical software SPSS version 21.0 (IBM, Armonk, USA).

With the few exceptions mentioned below, all analyses were performed separately in the two cohorts. As no significant statistical interaction by gender in the association between SES and inflammatory markers was found ( $p$ for the interaction $>0.05$ ), data were analysed together for men and women. hs-CRP, leukocyte count, IL-6, TNF- $\alpha$ and fibrinogen were categorized in tertiles and then the prevalence of high hs-CRP, high leukocyte count, high IL-6, high TNF- $\alpha$ and high fibrinogen levels was presented based on the highest tertile vs. the two lower tertiles. The association of demographic factors, health behaviours and chronic conditions with inflammatory markers was assessed using Logistic Regression, and the results were expressed as odds ratio (OR) and $95 \%$ confidence interval $(95 \% \mathrm{CI})$.

The association between socioeconomic indicators (education and occupational position) and inflammatory markers was assessed using Logistic Regression and three models were used: adjusted for age and gender (Model 1); adjusted for age, gender, marital status, current smoking, heavy drinking, inactivity, and BMI z-score (Model 2) and adjusted for age, gender, marital status, current smoking, heavy drinking, inactivity, BMI z-score, chronic disease and anti-inflammatory medication (Model 3). For the present analyses we considered age, sex, marital status and underlying chronic conditions as confounders, and smoking, heavy drinking, inactivity and BMI as potential mediators, although a clear distinction between confounders and mediators is difficult to make in cross-sectional studies.

Differences (and their 95\% CI) in inflammation between the highest and the lowest educational/occupational group were calculated using Linear Regression. Variables with skewed distributions (hs-CRP, IL-6, TNF- $\alpha$, leukocyte and fibrinogen) were log transformed for use in the Linear Regression models and the p-value for linear trend across socioeconomic categories was estimated.

In order to test whether the association between SES and inflammatory markers differed by cohort, an interaction term between SES and cohort was fitted in the regression models including both cohorts. Statistical significance was considered for $\mathrm{p}<0.05$.

\section{Results}

Table 1 shows the distribution of participants across the educational and occupational categories in the two cohorts. In both cohorts, participants with a low SES were older (with the exception of those with a low occupational position in CoLaus who tended to be younger). Participants with a low educational level and occupational position had a higher proportion of current smoking, heavy drinking, inactivity, $\mathrm{BMI} \geq 30 \mathrm{~kg} / \mathrm{m}^{2}$, chronic disease and anti-inflammatory drug use. Contrary to CoLaus, EPIPorto participants of low SES had a lower proportion of current smoking. In both cohorts, participants with a lower educational level tended to present high levels of inflammatory markers. Similarly, participants with a low occupational position had higher hs-CRP and TNF- $\alpha$ (only assessed in the CoLaus study) levels and fibrinogen (only assessed in the EPIPorto study) compared to those with a higher occupational position. High leukocyte count was more frequent among participants with a middle occupational position.

Table 2 shows the association between inflammatory markers and demographic factors, behavioural factors and chronic conditions in the two studies. Men were more likely to present high IL-6 (OR = 1.24; $95 \% \mathrm{CI}: 1.12,1.38)$ and TNF- $\alpha(\mathrm{OR}=1.26 ; 95 \% \mathrm{CI}: 1.13,1.40)$ compared to women. However, men were more likely than women to present lower values of fibrinogen ( $\mathrm{OR}=0.50 ; 95 \% \mathrm{CI}: 0.37,0.69$ ), similarly to those living in couple instead of alone ( $\mathrm{OR}=0.56$; $95 \% \mathrm{CI}: 0.41,0.76)$. In the two studies, current smoking, inactivity, BMI $\geq 30 \mathrm{~kg} / \mathrm{m}^{2}$ and chronic conditions were positively associated with high levels of circulating inflammatory markers.

Table 3 presents results for the association between inflammatory markers and education in the CoLaus and EPIPorto studies. The difference in the log of hs-CRP concentration between the lowest and the highest educational group was $\beta=0.31 ; 95 \% \mathrm{CI}=0.25,0.37$ in CoLaus and $\beta=0.26 ; 95 \% \mathrm{CI}=0.13,0.40$ in EPIPorto. When marital status and behavioural factors were added to the model, associations were reduced but remained statistically significant in the CoLaus cohort. Participants with a lower educational level had higher concentration of leukocytes and this association remained borderline significant $(p=0.063$ ) after adjustment for health behaviours. In the CoLaus study, significant associations were also found between IL-6 and education, but those more likely to have higher levels of IL-6 were participants with a middle educational level ( $O R=1.40$; $95 \%$ CI: 1.18, 1.65). TNF- $\alpha$ (measured in CoLaus) and fibrinogen (measured in EPIPorto) were not significantly patterned by education. When chronic conditions were added to Model 2 (Model 3), no significant changes were observed in the estimates.

Associations between occupational position and inflammatory markers in the two cohorts are presented in Table 4. As for education, an inverse association was found between hs-CRP and occupational position in both cohorts, i.e., the odds of high hs-CRP increased with decreasing occupational position. Also, when marital status and behavioural factors were added to the age and sex adjusted model, the odds ratio was 1.30 (95\% CI: 1.06, 1.60) in CoLaus and 1.13 (95\% CI: 0.80, 1.60) in EPIPorto among those with low education comparing with high education. After adjustment for chronic conditions, the linear trend remained significant only in the CoLaus study $(\mathrm{p}<0.001)$. In CoLaus, after adjustment for health behaviours, no significant linear trend was observed for IL- 6 and TNF- $\alpha$. In EPIPorto, leukocytes were significantly associated with occupational position, with participants in the middle occupational category being more likely to have higher levels. Fibrinogen was not significantly associated with occupational position. When chronic conditions were added to Model 2 (Model 3), no significant reduction was observed in the difference of inflammatory markers between the lowest and the highest occupational position.

We tested whether the association between SES and inflammatory markers differed in the two cohorts and no evidence was found for such an interaction ( $\mathrm{p}$ for the interaction $>0.05$ ).

\section{Sensitivity analyses}

We repeated the analysis for hs-CRP using the clinical threshold for high CRP (>3.0 mg/L). Results were similar to those presented using tertiles [see Tables S1 and S2].

Although analyses are adjusted for factors that we had hypothesized a priori as mediators or confounders of the SES-inflammation association, we performed a Stepwise Logistic Regression in order to observe the factors most strongly altering the point estimates. Results showed that BMI and inactivity were the strongest mediators of the SES-inflammation association [see Tables S3 and S4]. 
Table 1

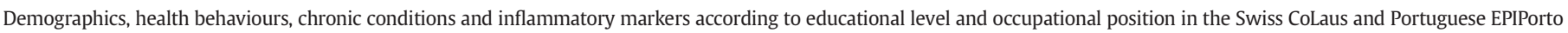
studies.

\begin{tabular}{|c|c|c|c|c|c|c|}
\hline & \multicolumn{3}{|c|}{ Education (\%) } & \multicolumn{3}{|c|}{ Occupation (\%) } \\
\hline & High & Medium & Low & High & Medium & Low \\
\hline CoLaus & $\mathrm{n}=1284$ & $\mathrm{n}=1555$ & $\mathrm{n}=3573$ & $\mathrm{n}=1832$ & $\mathrm{n}=1993$ & $\mathrm{n}=761$ \\
\hline \multicolumn{7}{|l|}{ Demographics } \\
\hline Age, mean (SD) & $49.6(9.8)$ & $51.9(10.6)$ & $53.7(10.8)^{*}$ & $48.9(8.8)$ & $49.6(8.8)$ & $48.2(8.5)^{\text {** }}$ \\
\hline Male & 57.2 & 45.3 & $45.4^{*}$ & 62.4 & 48.8 & $43.3^{*}$ \\
\hline Living in couple & 56.9 & 58.7 & $60.6^{* * *}$ & 59.1 & 53.6 & $65.1^{*}$ \\
\hline \multicolumn{7}{|l|}{ Health behaviours } \\
\hline Current smoking & 22.0 & 25.9 & $28.5^{*}$ & 24.0 & 32.2 & $31.0^{*}$ \\
\hline Heavy drinking & 8.1 & 7.8 & 8.4 & 8.2 & 9.0 & 8.7 \\
\hline Inactivity & 23.2 & 28.9 & $42.5^{*}$ & 23.5 & 38.5 & $57.3^{*}$ \\
\hline $\mathrm{BMI} \geq 30 \mathrm{~kg} / \mathrm{m}^{2}$ & 10.2 & 15.9 & $23.7^{*}$ & 12.3 & 19.0 & $21.7^{*}$ \\
\hline \multicolumn{7}{|l|}{ Chronic conditions } \\
\hline Chronic disease & 36.1 & 41.7 & $47.3^{*}$ & 34.8 & 39.9 & $41.9^{*}$ \\
\hline Anti-inflammatory medication & 2.1 & 4.3 & $5.8^{*}$ & 2.1 & 4.1 & $3.8^{*}$ \\
\hline \multicolumn{7}{|l|}{ Inflammatory markers } \\
\hline High hs-CRP & 24.8 & 31.2 & $39.0^{*}$ & 26.5 & 35.1 & $40.2^{*}$ \\
\hline High IL-6 & 29.4 & 36.5 & $33.4^{*}$ & 31.9 & 34.8 & 33.4 \\
\hline High TNF- $\alpha$ & 28.0 & 34.5 & $34.6^{*}$ & 31.7 & 33.4 & $37.0^{* * *}$ \\
\hline EPIPorto & $\mathrm{n}=301$ & $\mathrm{n}=181$ & $\mathrm{n}=723$ & $\mathrm{n}=421$ & $\mathrm{n}=329$ & $\mathrm{n}=349$ \\
\hline \multicolumn{7}{|l|}{ Demographics } \\
\hline Age, mean (SD) & $52.4(9.8)$ & $54.3(10.6)$ & $60.1(9.9)^{*}$ & $54.4(10.2)$ & $57.9(10.6)$ & $59.6(10.3)^{*}$ \\
\hline Male & 37.5 & 43.1 & $33.5^{* * * *}$ & 43.0 & 43.5 & $28.1^{*}$ \\
\hline Living in couple & 67.8 & 74.0 & 74.1 & 72.2 & 72.0 & 73.9 \\
\hline \multicolumn{7}{|l|}{ Health behaviours } \\
\hline Current smoking & 28.2 & 17.1 & $14.2^{*}$ & 24.5 & 18.9 & $12.1^{*}$ \\
\hline Heavy drinking & 10.0 & 22.3 & $25.2^{*}$ & 15.1 & 26.6 & $23.7^{*}$ \\
\hline Physical inactivity & 43.9 & 41.4 & $58.7^{*}$ & 42.5 & 48.3 & $67.7^{*}$ \\
\hline $\mathrm{BMI} \geq 30 \mathrm{~kg} / \mathrm{m}^{2}$ & 16.3 & 26.7 & $38.4^{*}$ & 18.8 & 30.6 & $43.0^{*}$ \\
\hline \multicolumn{7}{|l|}{ Chronic conditions } \\
\hline Chronic disease & 50.8 & 65.2 & $67.7^{*}$ & 54.4 & 64.4 & $70.7^{*}$ \\
\hline Anti-inflammatory medication & 4.3 & 6.1 & $12.3^{*}$ & 5.2 & 9.7 & $13.2^{* *}$ \\
\hline \multicolumn{7}{|l|}{ Inflammatory markers } \\
\hline High hs-CRP & 22.9 & 22.7 & $29.2^{* * *}$ & 29.0 & 32.8 & $40.7^{* *}$ \\
\hline High leukocyte count & 27.9 & 31.5 & 33.1 & 34.1 & 35.3 & 30.5 \\
\hline High fibrinogen & 26.0 & 29.6 & 30.3 & 31.4 & 34.1 & 34.8 \\
\hline
\end{tabular}

ANOVA or the Chi-square test.

$* \mathrm{p}<0.001$.

** $\mathrm{p}<0.01$.

$* * * \quad \mathrm{p}<0.05$.

Also, because categorizing chronic conditions as dichotomous variables might lead to loss of information, we have repeated the analysis on the SES distribution of chronic diseases separately for each disease [see Table S5]. Depression, hypertension and respiratory diseases were the most prevalent conditions in both countries and their prevalence was higher among low SES individuals.

\section{Discussion}

\section{SES and inflammatory markers}

Among adults from two European population based-studies, low SES was associated with higher levels of inflammation as measured through hs-CRP, interleukin-6, TNF- $\alpha$, leukocyte count and fibrinogen. These results are consistent with previous studies reporting associations between SES and chronic inflammation (Koster et al., 2006; Loucks et al., 2006; Stringhini et al., 2013). In both cohorts, the most consistent association was found for hs-CRP. CRP levels increased with lower education and with lower occupational position. However, in the CoLaus study the association of SES with hs-CRP seemed to be stronger and persisted after adjustment for marital status and behavioural factors. We should note that the effect of SES on inflammation did not significantly differ by cohort.

Similarly to hs-CRP, elevated blood leukocytes indicate an ongoing immune response, and a higher prevalence of chronic inflammatory conditions. After controlling for potential confounders/mediators, the association of leukocyte count with educational level and occupational position persisted in EPIPorto. Additionally, in the EPIPorto study, we observed that after adjustment for marital status and health behaviours the odds ratios for leukocyte count across education and occupational position increased. Because leukocyte and its components (particularly the granulocyte count) are strongly associated with cigarette smoking (Smith et al., 2003), we may speculate that the observed increase in odds ratios is explained by higher smoking prevalence among higher SES individuals in EPIPorto.

In EPIPorto, we observed an inverse association between SES and fibrinogen levels (lower SES individuals showing higher concentrations), although it did not persist after adjustment for confounders/ mediators. An inverse association between SES and fibrinogen was reported in other studies (Jousilahti et al., 2003; Wilson et al., 1993).

With regard to the association between SES and IL-6, results from previous studies were inconsistent. Most studies have found no significant associations between education, income or occupation and IL-6 (Brydon et al., 2004; Koster et al., 2006; Loucks et al., 2006). However, in another study employment grade was strongly inversely related to IL- 6 concentration after adjustment for age and sex (Hemingway et al., 2003). In the CoLaus study, we found a Ushaped association between SES and IL-6, with higher levels found in the middle educational and occupational group. Additionally, we observed a dose-response inverse association between occupational position and TNF- $\alpha$. For both inflammatory markers, associations were explained away after adjustment for behavioural factors. 
Table 2

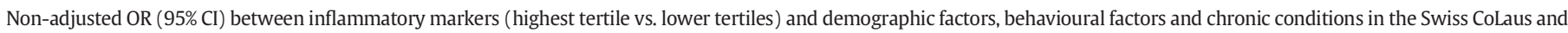
Portuguese EPIPorto studies.

\begin{tabular}{|c|c|c|c|c|c|c|}
\hline & \multicolumn{3}{|l|}{$\begin{array}{l}\text { CoLaus } \\
\mathrm{N}=6412\end{array}$} & \multicolumn{3}{|l|}{$\begin{array}{l}\text { EPIPorto } \\
\mathrm{N}=1205\end{array}$} \\
\hline & $\begin{array}{l}\text { High hs-CRP } \\
\text { OR ( } 95 \% \mathrm{CI})\end{array}$ & $\begin{array}{l}\text { High IL-6 } \\
\text { OR (95\% CI) }\end{array}$ & $\begin{array}{l}\text { High TNF- } \alpha \\
\text { OR }(95 \% \mathrm{CI})\end{array}$ & $\begin{array}{l}\text { High hs-CRP } \\
\text { OR (95\% CI) }\end{array}$ & $\begin{array}{l}\text { High leukocyte } \\
\text { OR }(95 \% \mathrm{CI})\end{array}$ & $\begin{array}{l}\text { High fibrinogen } \\
\text { OR }(95 \% \mathrm{CI})\end{array}$ \\
\hline \multicolumn{7}{|l|}{ Demographics } \\
\hline Gender (ref.: women) & $0.82(0.74,0.91)$ & $1.24(1.12,1.38)$ & $1.26(1.13,1.40)$ & $0.60(0.45,0.80)$ & $1.33(1.04,1.71)$ & $0.50(0.37,0.69)$ \\
\hline Age & $1.03(1.02,1.03)$ & $1.01(1.00,1.01)$ & $1.02(1.01,1.02)$ & $1.00(0.99,1.01)$ & $0.98(0.97,1.00)$ & $1.03(1.01,1.04)$ \\
\hline Living in couple (ref.: no) & $0.95(0.86,1.06)$ & $1.02(0.91,1,13)$ & $1.03(0.92,1.15)$ & $1.00(0.75,1.34)$ & $1.18(0.89,1.55)$ & $0.56(0.41,0.76)$ \\
\hline \multicolumn{7}{|l|}{ Health behaviours } \\
\hline Current smoking (ref.: no) & $1.19(1.06,1.33)$ & $1.38(1.22,1.55)$ & $1.14(1.01,1.29)$ & $1.25(0.90,1.72)$ & $4.05(2.99,5.50)$ & $1.25(0.86,1.80)$ \\
\hline Heavy drinking (ref.: no) & $1.22(1.02,1.47)$ & $1.40(1.16,1.70)$ & $1.23(1.02,1.49)$ & $0.97(0.71,1.34)$ & $0.81(0.59,1.10)$ & $0.56(0.39,0.81)$ \\
\hline Physical Inactivity (ref.: no) & $1.57(1.41,1.75)$ & $1.22(1.09,1.70)$ & $1.10(0.98,1.49)$ & $1.58(1.22,2.04)$ & $1.17(0.84,1.49)$ & $1.23(0.93,1.63)$ \\
\hline $\mathrm{BMI} \geq 30 \mathrm{~kg} / \mathrm{m}^{2}$ (ref.: no) & $3.76(3.30,4.28)$ & $1.40(1.23,1.60)$ & $1.55(1.36,1.77)$ & $2.19(1.68,2.86)$ & $1.31(1.01,1.69)$ & $1.55(1.16,2.07)$ \\
\hline \multicolumn{7}{|l|}{ Chronic conditions } \\
\hline Chronic disease (ref.: no) & $1.84(1.66,2.04)$ & $1.19(1.07,1.33)$ & $1.25(1.12,1.39)$ & $1.62(1.23,2.13)$ & $1.43(1.10,1.85)$ & $1.10(0.82,1.47)$ \\
\hline Anti-inflammatory medication (ref.: no) & $1.51(1.19,1.91)$ & $1.12(0.88,1.43)$ & $1.27(1.00,1.62)$ & $1.32(0.87,2.01)$ & $1.02(0.67,1.54)$ & $1.32(0.85,2.06)$ \\
\hline
\end{tabular}

High inflammatory marker corresponds to high tertile vs. lower tertiles.

Role of demographic factors, behavioural factors and chronic conditions

As a general pattern, behavioural factors seemed to explain a substantial part of SES differences in inflammatory marker levels. An unhealthy lifestyle, including smoking, heavy drinking, physical inactivity and BMI $\geq 30 \mathrm{~kg} / \mathrm{m}^{2}$ is generally more prevalent in low vs. high SES groups and is also related to higher chronic inflammation.
An exception is current smoking in Portugal, where people with a high vs. low SES are more likely to smoke (Cavelaars et al., 2000; Santos and Barros, 2004). Smoking has been significantly associated with increased inflammatory activity (Levitzky et al., 2008) and may be one of the mechanisms through which education influences inflammatory marker concentrations. Because of its different SES distribution in the two cohorts, in EPIPorto smoking is probably masking the effect

Table 3

Association between inflammatory markers and educational level in the Swiss CoLaus and Portuguese EPIPorto studies.

\begin{tabular}{|c|c|c|c|c|c|c|}
\hline & \multicolumn{3}{|c|}{ Education } & \multirow[t]{2}{*}{$\Delta^{\mathrm{b}}$} & \multirow[t]{2}{*}{$(95 \% \mathrm{CI})$} & \multirow[t]{2}{*}{$\mathrm{p}^{\mathrm{c}}$} \\
\hline & $\begin{array}{l}\text { High } \\
\mathrm{OR}^{\mathrm{a}}\end{array}$ & $\begin{array}{l}\text { Medium } \\
\mathrm{OR}^{\mathrm{a}}(95 \% \mathrm{CI})\end{array}$ & $\begin{array}{l}\text { Low } \\
\text { OR }^{\mathrm{a}}(95 \% \mathrm{CI})\end{array}$ & & & \\
\hline \multicolumn{7}{|l|}{ CoLaus } \\
\hline \multicolumn{7}{|l|}{ hs-CRP } \\
\hline Model 1 & 1.00 & $1.27(1.08,1.51)$ & $1.72(1.49,1.99)$ & 0.31 & $0.25,0.37$ & $<0.001$ \\
\hline Model 2 & 1.00 & $1.09(0.91,1.30)$ & $1.20(1.02,1.40)$ & 0.11 & $0.05,0.16$ & $<0.001$ \\
\hline Model 3 & 1.00 & $1.09(0.91,1.30)$ & $1.20(1.02,1.40)$ & 0.11 & $0.05,0.16$ & $<0.001$ \\
\hline \multicolumn{7}{|l|}{ IL-6 } \\
\hline Model 1 & 1.00 & $1.40(1.18,1.65)$ & $1.21(1.04,1.40)$ & 0.10 & $0.01,0.21$ & 0.050 \\
\hline Model 2 & 1.00 & $1.31(1.10,1.55)$ & $1.06(0.91,1.23)$ & 0.01 & $-0.11,0.11$ & 0.998 \\
\hline Model 3 & 1.00 & $1.30(1.10,1.54)$ & $1.05(0.91,1.23)$ & 0.01 & $-0.11,0.11$ & 0.999 \\
\hline \multicolumn{7}{|l|}{ TNF- $\alpha$} \\
\hline Model 1 & 1.00 & $1.34(1.13,1.59)$ & $1.30(1.12,1.51)$ & 0.07 & $0.01,0.13$ & 0.030 \\
\hline Model 2 & 1.00 & $1.28(1.08,1.52)$ & $1.18(1.01,1.38)$ & 0.03 & $-0.03,0.09$ & 0.374 \\
\hline Model 3 & 1.00 & $1.28(1.08,1.52)$ & $1.18(1.01,1.38)$ & 0.03 & $-0.03,0.09$ & 0.350 \\
\hline \multicolumn{7}{|l|}{ EPIPorto } \\
\hline \multicolumn{7}{|l|}{ hs-CRP } \\
\hline Model 1 & 1.00 & $1.03(0.66,1.60)$ & $1.42(1.02,1.98)$ & 0.26 & $0.13,0.40$ & $<0.001$ \\
\hline Model 2 & 1.00 & $0.92(0.56,1.52)$ & $1.25(0.85,1.83)$ & 0.11 & $-0.03,0.25$ & 0.130 \\
\hline Model 3 & 1.00 & $0.89(0.54,1.46)$ & $1.21(0.82,1.78)$ & 0.10 & $-0.04,0.24$ & 0.168 \\
\hline \multicolumn{7}{|l|}{ Leukocyte } \\
\hline Model 1 & 1.00 & $1.26(0.84,1.89)$ & $1.53(1.12,2.09)$ & 0.04 & $0.01,0.08$ & 0.014 \\
\hline Model 2 & 1.00 & $1.43(0.90,2.27)$ & $1.68(1.16,2.44)$ & 0.03 & $-0.002,0.07$ & 0.063 \\
\hline Model 3 & 1.00 & $1.35(0.84,2.15)$ & $1.64(1.13,2.38)$ & 0.03 & $-0.003,0.07$ & 0.071 \\
\hline \multicolumn{7}{|l|}{ Fibrinogen } \\
\hline Model 1 & 1.00 & $1.10(0.68,1.78)$ & $0.95(0.65,1.39)$ & -0.004 & $-0.04,0.03$ & 0.818 \\
\hline Model 2 & 1.00 & $0.99(0.59,1.67)$ & $0.98(0.65,1.49)$ & 0.004 & $-0.03,0.04$ & 0.839 \\
\hline Model 3 & 1.00 & $1.02(0.60,1.72)$ & $1.00(0.66,1.53)$ & 0.005 & $-0.03,0.04$ & 0.807 \\
\hline
\end{tabular}

a Odds ratios (ORs) and 95\% confidence intervals (95\% CIs) were calculated through a Logistic Regression.Model $1=$ adjusted for age and gender.Model $2=$ adjusted for age, gender,

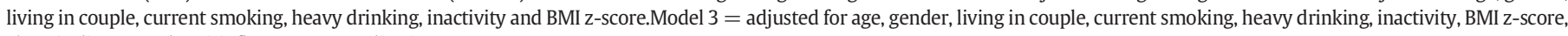
chronic disease and anti-inflammatory medication.

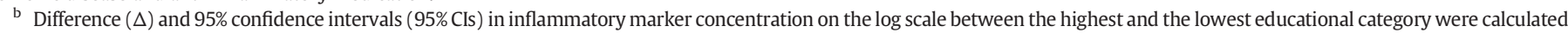
through Linear Regression.

c p-Value for linear trend across education categories. 
Association between inflammatory markers and occupational position in the Swiss CoLaus and Portuguese EPIPorto studies.

\begin{tabular}{|c|c|c|c|c|c|c|}
\hline & \multicolumn{3}{|c|}{ Occupation } & \multirow[t]{2}{*}{$\Delta^{\mathrm{b}}$} & \multirow[t]{2}{*}{$(95 \% \mathrm{CI})$} & \multirow[t]{2}{*}{$\mathrm{p}^{\mathrm{c}}$} \\
\hline & $\begin{array}{l}\text { High } \\
\text { OR }^{\mathrm{a}}\end{array}$ & $\begin{array}{l}\text { Medium } \\
\text { OR }^{\mathrm{a}}(95 \% \mathrm{CI})\end{array}$ & $\begin{array}{l}\text { Low } \\
\text { OR }^{\text {a }}(95 \% \mathrm{CI})\end{array}$ & & & \\
\hline \multicolumn{7}{|l|}{ CoLaus } \\
\hline \multicolumn{7}{|l|}{ hs-CRP } \\
\hline Model 1 & 1.00 & $1.48(1.29,1.71)$ & $1.92(1.60,2.30)$ & 0.38 & $0.30,0.46$ & $<0.001$ \\
\hline Model 2 & 1.00 & $1.16(1.00,1.36)$ & $1.30(1.06,1.60)$ & 0.16 & $0.09,0.24$ & $<0.001$ \\
\hline Model 3 & 1.00 & $1.17(1.00,1.36)$ & $1.30(1.06,1.60)$ & 0.16 & $0.09,0.24$ & $<0.001$ \\
\hline \multicolumn{7}{|l|}{ IL-6 } \\
\hline Model 1 & 1.00 & $1.16(1.01,1.33)$ & $1.12(0.93,1.36)$ & 0.23 & $0.09,0.37$ & 0.002 \\
\hline Model 2 & 1.00 & $1.06(0.92,1.23)$ & $1.02(0.83,1.24)$ & 0.12 & $-0.03,0.26$ & 0.117 \\
\hline Model 3 & 1.00 & $1.07(0.92,1.24)$ & $1.02(0.83,1.25)$ & 0.12 & $-0.02,0.27$ & 0.097 \\
\hline \multicolumn{7}{|l|}{ TNF- $\alpha$} \\
\hline Model 1 & 1.00 & $1.11(0.96,1.28)$ & $1.36(1.13,1.64)$ & 0.09 & $0.01,0.18$ & 0.021 \\
\hline Model 2 & 1.00 & $1.03(0.89,1.19)$ & $1.25(1.02,1.49)$ & 0.05 & $-0.03,0.13$ & 0.249 \\
\hline Model 3 & 1.00 & $1.03(0.89,1.20)$ & $1.25(1.02,1.53)$ & 0.05 & $-0.03,0.14$ & 0.195 \\
\hline \multicolumn{7}{|l|}{$\begin{array}{l}\text { EPIPorto } \\
\qquad \mathrm{N}=1099\end{array}$} \\
\hline \multicolumn{7}{|l|}{ hs-CRP } \\
\hline Model 1 & 1.00 & $1.16(0.85,1.59)$ & $1.51(1.11,2.06)$ & 0.32 & $0.17,0.46$ & $<0.001$ \\
\hline Model 2 & 1.00 & $0.99(0.71,1.39)$ & $1.13(0.80,1.60)$ & 0.12 & $-0.02,0.26$ & 0.104 \\
\hline Model 3 & 1.00 & $0.98(0.70,1.37)$ & $1.11(0.79,1.57)$ & 0.11 & $-0.03,0.25$ & 0.138 \\
\hline \multicolumn{7}{|l|}{ Leukocyte } \\
\hline Model 1 & 1.00 & $1.61(1.18,2.20)$ & $1.49(1.09,2.05)$ & 0.05 & $0.01,0.08$ & 0.009 \\
\hline Model 2 & 1.00 & $1.75(1.24,2.46)$ & $1.57(1.10,2.25)$ & 0.03 & $-0.003,0.07$ & 0.072 \\
\hline Model 3 & 1.00 & $1.71(1.21,2.42)$ & $1.54(1.07,2.21)$ & 0.03 & $-0.004,0.07$ & 0.082 \\
\hline \multicolumn{7}{|l|}{ Fibrinogen } \\
\hline Model 1 & 1.00 & $1.00(0.70,1.43)$ & $0.88(0.61,1.27)$ & -0.014 & $-0.05,0.02$ & 0.459 \\
\hline Model 2 & 1.00 & $0.99(0.68,1.43)$ & $0.87(0.58,1.28)$ & -0.013 & $-0.05,0.02$ & 0.498 \\
\hline Model 3 & 1.00 & $1.00(0.69,1.45)$ & $0.89(0.60,1.32)$ & -0.013 & $-0.05,0.02$ & 0.519 \\
\hline
\end{tabular}

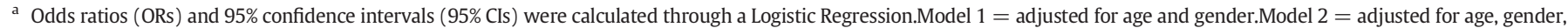

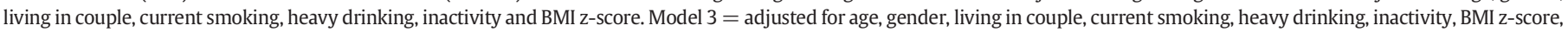
chronic disease and anti-inflammatory medication.

b Difference $(\Delta)$ and $95 \%$ confidence intervals (95\% CIs) in inflammatory marker concentration on the log scale between the highest and the lowest occupational category were calculated through Linear Regression.

c p-Value for linear trend across occupational categories.

of SES on inflammation while in CoLaus it is probably enhancing it. $\mathrm{BMI} \geq 30 \mathrm{~kg} / \mathrm{m}^{2}$ is also inversely related to SES and may be important to explain the association between SES and inflammation because IL-6 and TNF- $\alpha$, for example, are produced within adipose tissue (Coppack, 2001). These markers are a primary stimulus for hs-CRP production in the liver and may trigger a cascade of inflammation (Coppack, 2001). Marital status was also considered a confounder although, with the exception of fibrinogen in EPIPorto, no association was found between marital status and inflammatory markers in this analysis. Although heavy drinking was generally positively associated with most inflammatory markers, it was negatively associated with fibrinogen levels in the Portuguese sample. This finding was reported in other studies (Galan et al., 2014; Sierksma et al., 2002) although the specific mechanisms or a plausible explanation remains uncertain.

Additionally, chronic conditions may explain part of the association between SES and inflammation. People with low SES were more likely to present a chronic disease and they also had higher levels of inflammation. However, after controlling for chronic conditions, no significant changes were observed in the associations.

In our study, we assessed two important indicators of SES such as education and occupational position in relation to several inflammatory markers in two European countries with different social and economic realities. It was not possible to examine the potential importance of individual income or financial strain for SES differences in inflammation, because this indicator was not available in any of the cohorts. However, other studies have shown that inflammatory markers were significantly negatively associated with income (Friedman and Herd, 2010). Additionally, other psychosocial factors may contribute to explain the association between SES and inflammation, for example social support. It is known that social support may contribute to buffer the impact of stressors (Taylor and Seeman, 1999). Therefore, psychosocial resources should be further explored as potential mediators in order to better understand the relationship between SES and chronic inflammation.

\section{SES and country-specific characteristics}

Individual SES can also be a result of the social and economic context in which individuals live and grow. In the present study, we compared social differences in inflammation in two population samples from two European cities with different socioeconomic realities. Recent data from the Organization for Economic Co-operation and Development (OECD) (OECD, 2013) shows that the Swiss gross domestic product per capita was more than double than that of Portugal in 2012. Also, unemployment rate is higher in Portugal than in Switzerland (15.9\% vs. $4.2 \%$ ). Another important country indicator of a country's degree of economic inequality is the Gini coefficient that represents the distribution of income in a population. The Gini coefficient in 2012 was 0.345 in Portugal and 0.288 in Switzerland, showing higher levels of inequality in Portugal. Despite the contextual differences between these two countries, we showed that the association of SES with inflammation is similar in a Portuguese and a Swiss city, suggesting that the context in which people has little impact on the social patterning of inflammation.

\section{Strengths and limitations}

The main strength of this study was the opportunity of using data from two different cohorts that have collected similar data allowing comparison between two different European settings. This study also has potential limitations. First, for analysis on occupational position we excluded participants that were not working and therefore not 
classifiable in their occupational position. In the Swiss cohort, almost $30 \%$ of the participants were excluded for analysis. Although it is not possible to know why these individuals were not working, given the higher proportion of women and elderly among the non-working participants we speculate that most were retired or non-working by their own option instead of unemployed. Second, in both studies, health behaviours were self-reported which may result in some misclassification of individual risk status. Third, it was not possible to have the same inflammatory markers in both cohorts (with the exception of hs-CRP) although available data confirmed the important role of socioeconomic status for these biological markers. Fourth, in our analysis we defined high values of inflammation based on the top tertile of each inflammatory marker, which is very dependent on the population distribution of the markers. However, most of the inflammatory markers, including those we use here, do not have defined clinical cutoffs that can be used instead of distribution-based cutoffs.

\section{Conclusions}

Our results suggest that large social differences exist in inflammatory activity, and that these differences are similar using different indicators of SES and in different countries with different underlying socioeconomic conditions. Further research should explore the extent to which such differences in inflammatory activity contribute to explain, at least in part, social inequalities in inflammation-related diseases.

\section{Funding}

The CoLaus study was supported by research grants from GlaxoSmithKline, the Faculty of Biology and Medicine, University Hospital Center of Lausanne Switzerland, and the Swiss National Science Foundation (grants no.: 33CSCO-122661, 33CS30-139468 and 33CS30-148401). The EPIPorto study was funded by Fundação para a Ciência e a Tecnologia, POCTI/ESP/42361/2001, POCI/SAU-ESP/61160/ 2004, and PTDC/SAU-ESA/108315/2008. Sílvia Fraga is the recipient of a Post Doc grant from Fundação para a Ciência e a Tecnologia (SFRH/ BPD/97015/2013). Silvia Stringhini is supported by an Ambizione Grant (no. PZOOP3_147998) from the Swiss National Science Foundation.

\section{Conflict of interest statement}

The authors declare that there are no conflicts of interests.

\section{Appendix A. Supplementary data}

Supplementary data to this article can be found online at http://dx. doi.org/10.1016/j.ypmed.2014.11.031.

\section{References}

Adler, N.E., Boyce, W.T., Chesney, M.A., Folkman, S., Syme, S.L., 1993. Socioeconomic inequalities in health. No easy solution. JAMA 269, 3140-3145.

Alley, D.E., Seeman, T.E., Ki Kim, J., Karlamangla, A., Hu, P., Crimmins, E.M., 2006. Socioeconomic status and C-reactive protein levels in the US population: NHANES IV. Brain Behav. Immun. 20, 498-504.

Allin, K.H., Nordestgaard, B.G., 2011. Elevated C-reactive protein in the diagnosis, prognosis, and cause of cancer. Crit. Rev. Clin. Lab. Sci. 48, 155-170.

Brydon, L., Edwards, S., Mohamed-Ali, V., Steptoe, A., 2004. Socioeconomic status and stress-induced increases in interleukin-6. Brain Behav. Immun. 18, 281-290.

Cavelaars, A., Kunst, A.E., Geurts, J.J.M., Crialesi, R., Grotvedt, L., Helmert, U., Lahelma, E., Lundberg, O., Matheson, J., et al., 2000. Educational differences in smoking: international comparison. BMJ 320, 1102-1107.

Cohen, S., 1999. Social status and susceptibility to respiratory infections. Ann. N. Y. Acad. Sci. 896, 246-253.

Cohen, S., Doyle, W.J., Turner, R.B., Alper, C.M., Skoner, D.P., 2004. Childhood socioeconomic status and host resistance to infectious illness in adulthood. Psychosom. Med. 66, 553-558.

Colbert, L.H., Visser, M., Simonsick, E.M., Tracy, R.P., Newman, A.B., Kritchevsky, S.B., Pahor, M., Taaffe, D.R., Brach, J., et al., 2004. Physical activity, exercise, and inflammatory markers in older adults: findings from the health, aging and body composition study. J. Am. Geriatr. Soc. 52, 1098-1104.
Coppack, S.W., 2001. Pro-inflammatory cytokines and adipose tissue. Proc. Nutr. Soc. 60 349-356.

Deverts, D.J., Cohen, S., Kalra, P., Matthews, K.A., 2012. The prospective association of socioeconomic status with C-reactive protein levels in the CARDIA study. Brain Behav. Immun. 26, 1128-1135.

Duncan, B.B., Schmidt, M.I., Pankow, J.S., Ballantyne, C.M., Couper, D., Vigo, A., Hoogeveen, R., Folsom, A.R., Heiss, G., et al., 2003. Low-grade systemic inflammation and the development of type 2 diabetes: the atherosclerosis risk in communities study. Diabetes 52, 1799-1805.

Fahdi, I.E., Gaddam, V., Garza, L., Romeo, F., Mehta, J.L., 2003. Inflammation, infection, and atherosclerosis. Brain Behav. Immun. 17, 238-244.

Firmann, M., Mayor, V., Vidal, P.M., Bochud, M., Pecoud, A., Hayoz, D., Paccaud, F., Preisig M., Song, K.S., et al., 2008. The CoLaus study: a population-based study to investigate the epidemiology and genetic determinants of cardiovascular risk factors and metabolic syndrome. BMC Cardiovasc. Disord. 8, 6.

Friedman, E.M., Herd, P., 2010. Income, education, and inflammation: differential associations in a national probability sample (The MIDUS study). Psychosom. Med. 72, 290-300.

Frohlich, M., Sund, M., Lowel, H., Imhof, A., Hoffmeister, A., Koenig, W., 2003. Independent association of various smoking characteristics with markers of systemic inflammation in men. Results from a representative sample of the general population (MONICA Augsburg Survey 1994/95). Eur. Heart J. 24, 1365-1372.

Galan, I., Valencia-Martin, J.L., Guallar-Castillon, P., Rodriguez-Artalejo, F., 2014. Alcohol drinking patterns and biomarkers of coronary risk in the Spanish population. Nutr. Metab. Cardiovasc. Dis. 24, 189-197.

Galobardes, B., Shaw, M., Lawlor, D.A., Lynch, J.W., Davey Smith, G., 2006a. Indicators of socioeconomic position (part 2). J. Epidemiol. Community Health 60, 95-101.

Galobardes, B., Smith, G.D., Lynch, J.W., 2006b. Systematic review of the influence of childhood socioeconomic circumstances on risk for cardiovascular disease in adulthood. Ann. Epidemiol. 16, 91-104.

Harris, T.B., Ferrucci, L., Tracy, R.P., Corti, M.C., Wacholder, S., Ettinger Jr., W.H., Heimovitz, H., Cohen, H.J., Wallace, R., 1999. Associations of elevated interleukin-6 and C-reactive protein levels with mortality in the elderly. Am. J. Med. 106, 506-512.

Hemingway, H., Shipley, M., Mullen, M.J., Kumari, M., Brunner, E., Taylor, M., Donald, A.E., Deanfield, J.E., Marmot, M., 2003. Social and psychosocial influences on inflammatory markers and vascular function in civil servants (the Whitehall II study). Am. J. Cardiol. 92, 984-987.

Hornung, R., Reed, L., 1990. Estimation of average concentration in the presence of nondectable values. Appl. Occup. Environ. Hyg. 5, 46-51.

Imhof, A., Froehlich, M., Brenner, H., Boeing, H., Pepys, M.B., Koenig, W., 2001. Effect of alcohol consumption on systemic markers of inflammation. Lancet 357, 763-767.

Jousilahti, P., Salomaa, V., Rasi, V., Vahtera, E., Palosuo, T., 2003. Association of markers of systemic inflammation, $C$ reactive protein, serum amyloid $A$, and fibrinogen, with socioeconomic status. J. Epidemiol. Community Health 57, 730-733.

Kaplan, G.A., Keil, J.E., 1993. Socioeconomic factors and cardiovascular disease: a review of the literature. Circulation 88, 1973-1998.

Koster, A., Bosma, H., Penninx, B.W., Newman, A.B., Harris, T.B., van Eijk, J.T., Kempen, G.I., Simonsick, E.M., Johnson, K.C., et al., 2006. Association of inflammatory markers with socioeconomic status. J. Gerontol. A Biol. Sci. Med. Sci. 61, 284-290.

Lawlor, D.A., Davey Smith, G., Ebrahim, S., 2003. Life course influences on insulin resistance: findings from the British Women's Heart and Health Study. Diabetes Care 26, 97-103.

Levitzky, Y.S., Guo, C.Y., Rong, J., Larson, M.G., Walter, R.E., Keaney, J.F., Sutherland, P.A Vasan, A. Lipinska, I., et al., 2008. Relation of smoking status to a panel of inflammatory markers: the Framingham offspring. Atherosclerosis 201, 217-224.

Loucks, E.B., Sullivan, L.M., Hayes, L.J., D'Agostino Sr., R.B., Larson, M.G., Vasan, R.S. Benjamin, E.J., Berkman, L.F., 2006. Association of educational level with inflammatory markers in the Framingham offspring study. Am. J. Epidemiol. 163, 622-628.

Marques-Vidal, P., Bochud, M., Bastardot, F., Luscher, T., Ferrero, F., Gaspoz, J.M. Paccaud, F., Urwyler, A., von Kanel, R., et al., 2011. Levels and determinants of inflammatory biomarkers in a Swiss population-based sample (CoLaus study). PLOS ONE 6, e21002.

OECD, 2013. Revenue Statistics 2013. In: Publishing, O. (Ed.), OECD Publishing.

Pearson, T.A., Mensah, G.A., Alexander, R.W., Anderson, J.L., Cannon 3rd, R.O., Criqui, M. Fadl, Y.Y., Fortmann, S.P., Hong, Y., et al., 2003. Markers of inflammation and cardiovascular disease: application to clinical and public health practice: a statement for healthcare professionals from the Centers for Disease Control and Prevention and the American Heart Association. Circulation 107, 499-511.

Pereira, M., Lunet, N., Paulo, C., Severo, M., Azevedo, A., Barros, H., 2012. Incidence of hypertension in a prospective cohort study of adults from Porto, Portugal. BMC Cardiovasc. Disord. 12, 114.

Pradhan, A.D., Manson, J.E., Rifai, N., Buring, J.E., Ridker, P.M., 2001. C-reactive protein, interleukin 6, and risk of developing type 2 diabetes mellitus. JAMA 286, 327-334.

Reuben, D.B., Cheh, A.I., Harris, T.B., Ferrucci, L., Rowe, J.W., Tracy, R.P., Seeman, T.E., 2002 Peripheral blood markers of inflammation predict mortality and functional decline in high-functioning community-dwelling older persons. J. Am. Geriatr. Soc. 50, 638-644.

Santos, A.C., Barros, H., 2003. Prevalence and determinants of obesity in an urban sample of Portuguese adults. Public Health 117, 430-437.

Santos, A.C., Barros, H., 2004. Smoking patterns in a community sample of Portuguese adults, 1999-2000. Prev. Med. 38, 114-119.

Siegrist, J., Marmot, M., 2004. Health inequalities and the psychosocial environment-two scientific challenges. Soc. Sci. Med. 58, 1463-1473.

Sierksma, A., van der Gaag, M.S., Kluft, C., Hendriks, H.F., 2002. Moderate alcohol consumption reduces plasma C-reactive protein and fibrinogen levels; a randomized, diet-controlled intervention study. Eur. J. Clin. Nutr. 56, 1130-1136. 
Smith, M.R., Kinmonth, A.L., Luben, R.N., Bingham, S., Day, N.E., Wareham, N.J., Welch, A Khaw, K.T., 2003. Smoking status and differential white cell count in men and women in the EPIC-Norfolk population. Atherosclerosis 169, 331-337.

Stringhini, S., Batty, G.D., Bovet, P., Shipley, M.J., Marmot, M.G., Kumari, M., Tabak, A.G. Kivimaki, M., 2013. Association of lifecourse socioeconomic status with chronic inflammation and type 2 diabetes risk: the Whitehall II prospective cohort study. PLoS Med. 10, e1001479.

Stringhini, S., Spencer, B., Marques-Vidal, P. Waeber, G., Vollenweider, P., Paccaud, F. Bovet, P., 2012a. Age and gender differences in the social patterning of cardiovascular risk factors in Switzerland: the CoLaus study. PLoS ONE 7, e49443.

Stringhini, S., Tabak, A.G., Akbaraly, T.N., Sabia, S., Shipley, M.J., Marmot, M.G., Brunner, E.J., Batty, G.D., Bovet, P., et al., 2012b. Contribution of modifiable risk factors to social inequalities in type 2 diabetes: prospective Whitehall II cohort study. BMJ 345, e5452.

Taylor, S.E., Seeman, T.E., 1999. Psychosocial resources and the SES-health relationship. Ann. N. Y. Acad. Sci. 896, 210-225.
UNESCO, 2011. International Standard Classification of Education. UNESCO.

Vignali, D.A., 2000. Multiplexed particle-based flow cytometric assays. J. Immunol. Methods 243, 243-255.

Willerson, J.T., Ridker, P.M., 2004. Inflammation as a cardiovascular risk factor. Circulation 109, II2-II10.

Wilson, T.W., Kaplan, G.A., Kauhanen, J., Cohen, R.D., Wu, M., Salonen, R., Salonen, J.T., 1993. Association between plasma fibrinogen concentration and five socioeconomic indices in the Kuopio Ischemic Heart Disease Risk Factor Study. Am. J. Epidemiol. 137, 292-300.

World Health Organization, 2007. The Challenge of Obesity in the WHO European Region and the Strategies for Response. WHO, Geneva. 